\title{
The Possibility of Parasitic Tobacco Roots Causing Nicotine Bitterness in Maize Grains
}

\author{
Kimatu JN* \\ Department of Biology, South Eastern Kenya University. P.O. Box 170-90200, Kitui, Kenya \\ *Corresponding Author: Josphert N Kimatu, Department of Biology, South Eastern \\ Kenya University. P.O. Box 170-90200, Kitui, Kenya, Tel: 734907740; Email: \\ jkimatu@seku.ac.ke
}

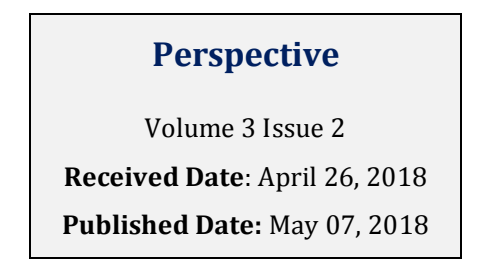

\begin{abstract}
Much has been said of the impact of smoking tobacco, but little has been said concerning ingesting tobacco. However, interacting with tobacco by chewing, smoking or ingesting has consequences. The UN Sustainable Development Goals (Target 3A) does not assume the significant impact posed by our interactions with tobacco products, but it advocates a need for reduction in usage. Governments have used the higher taxation on tobacco products and deliberate written campaigns on the dangers of tobacco products. The environmentalists have also raised concern on air pollution and the impact of cigarrete butts on the ecosystems. However, the agricultural sector and plant breeders have not shade enough light on the observed impact of growing tobacco in crop areas. This preliminary report is presented so as to sensitize other researchers to investigate its molecular and phenotypic implications.
\end{abstract}

Keywords: Food Security; Cigarettes; Pollution; Molecular; Solanales; Haustoria; Kenya

\section{Introduction}

One of the driving cross-cutting force of the sustainable developmental goals is that even the key drivers of development cannot be considered in isolation; because they are influenced significantly by other factors. The present status of the problems caused by tobacco usage dictates that it be up scaled from being an individual's problem or simply an indoor single-family pollution problem to a world-wide humanity problem. For every user of tobacco also affects another innocent human either directly or indirectly. Tobacco smoking is by far the most known way of influencing the health and environment of humanity [1]. At the genomic level, cigarette smoking has been shown to alter the epigenome during developmental processes. This accounts for an annual death of more than 7 million people. Sadly, this is a preventable cause of death. The range of social and economic damages from tobacco start from its farming, industrial processing, market distribution, various consumption methods, and lastly the post-consumer waste pollution on the environment. The health effects of farming tobacco have not been fully analyzed to date.

Studies on tobacco show that it is a real threat to the earth's resources. This includes human resources affected by cancer due to the tobacco smoke. Air as a resource is also directly affected by tobacco usage. Food resources have also been affected by tobacco growing although this has not been investigated to the fullest. The lack of much 


\section{Food Science and Nutrition Technology}

information on the Tobacco impact on food resources and health has largely been caused by large scale monoculture in developed countries and less research in small scale mixed farming systems in developing countries. However, there has been a shift from developed countries into developed countries to grow more tobacco in recent decades [2].

Tobacco has been affecting food production in developing countries by being a hyper soil nutrient extractor. Studies have shown that compared to other crops, tobacco absorbs much more nitrogen, phosphorus and potassium [3]. This study suggests that this craving of tobacco for minerals makes it to grow towards other plants and interacts with their roots to obtain these nutrients. As it does this, it introduces an internal molecular interaction in the roots of the plants and causes the production of nicotine in the plant making it to taste bitter. This is evidenced by studies which show that tobacco plant can grow as a parasitic plant. Parasitic plants utilize host plants for nutrients, water using intrusive roots called haustoria which enter host tissues . Studies have shown that parasitic plants do occur in all types of terrestrial ecosystems as either hemiparasites of holoparasites [4]. They reduce these plant resources by making them to produce less flowers, fewer viable seeds while some plant parasites have been known to kill their hosts [5].

\section{Effects of interacting with tobacco in the field}

There are evidences of physiological effects on health from persons growing or harvesting tobacco. For example, in India, workers in tobacco farms have been reported to suffer ill due to the absorption of nicotine through their skin when they exposed themselves to tobacco leaves in farms. The effects in the body after this absorption include headaches, breathlessness, loss of appetite, vomiting and weaknesses. Bitterness of tobacco leaves has also been reported to be passed to the foods which are prepared in homesteads where tobacco leaves are stored.

\section{Consumption of Tobacco Contaminated Maize}

In Africa, specifically in Machakos County, in Kenya, more than $80 \%$ of the farmers are small scale subsistence farmers who practice mainly mixed cropping. People of the order generation in Africa used to plant maize and tobacco together is the same farm for many seasons. This maize was mixed with beans and sometimes green vegetables to cook a staple food called Githeri. The families usually ate together but each member of the family was served separately in bowls. If a Githeri meal was served to let's say ten members of a family at one sitting, and the maize used was grown in a farm which had tobacco plants, about five of them will complain of encountering very bitter maize grains. These grains are so bitter that one has to spit a mouthful of food in disgust.

Morphological examination of these bitter grains, does not reveal much physically for some appear coloured black and others are colourless. The discovery of this relationship between bitter maize and tobacco grown in the farms has been a common knowledge amongst the locals but scientific studies at both morphological and molecular levels have not been done. This trend led to some farmers abandoning the growing of tobacco in maize farms.

\section{Possible modes of interaction of Tobacco with maize}

Plants can directly interact with other plants either parasitically or mutually and can transmit metabolic products or can incorporate its genome into the host plant. Tobacco plant is classified in the order Solanales. This order is famed for its production of poisonous alkaloids. Nicotiana tabacum or tobacco has nicotine which is toxic. Solanales is amongst the 12 orders that have represented independent evolutionary events that have given rise to parasitic angiosperms. (http://parasiticplants.siu.edu/ListPara sites.html).The determinants of the establishment of parasite-host interaction include genetics and biochemical tissue compatibility, geographical distribution) and dispersal biology and other environmental factors [5]. This report suggests that, this can be determined by comparing the transpiration rates and water potentials of the two interacting plants. This is because a parasitic plant will tend to have high transpiration rates but lower water potentials than the host plant. The absorption of nutrients may follow the apoplastic pathway [6]. Other parasitic markers that can be used include identification of mitochondrial rich haustorial cells along the xylem connections, an increased enzyme actions in haustoria cells, analysis of cell xylem saps differences [7-11].

\section{References}

1. World Health Organization (2017) Tobacco and its environmental impact: an overview.

2. Cairney P, Studlar DT, Mamudu HM (2011) Global Tobacco Control: Power, Policy, Governance and Transfer. 


\section{Food Science and Nutrition Technology}

3. Technical report (2001) Golden leaf barren harvest, the costs of tobacco farming. Washington DC. Campaign for Tobacco Free Kids.

4. Tesitel J, Plavcova L, Cameron DD (2010) Heterotrophic carbon gain by the root hemiparasites, Rhinanthus minor and Euphrasia rostkoviana (Orobanchaceae). Planta 231(5): 1137-1144.

5. Rubiales Diego, Heide-Jorgensen, Henning S (2011) Parasitic Plants. In: Encyclopedia of Life Sciences (ELS). John Wiley and Sons, Ltd: Chichester.

6. Ehleringer JR, Marshall JD (1995) Water relations. In: M C Press and J D Graves (eds) Parasitic Plants, London. Chapman \& Hall 125-140.

7. Ba AT, Kahlem G (1979) Mise ene'videnced'activate'senzymatiques au niveau de l'haustoriumd'unephane'rogame parasite; Striga hermonthica (scrophulariaceae). Canadian Journal of Botany 57: 2564-2567.
8. Kuo J, Pate JS, Davidson NJ (1989) Ultrastructure of the haustorial interface and apoplastic continuum between host and the root parasite Olaxphyllanthi (Labill.) R. Br. (Olacaceae). Protoplasma 150(1): 2739.

9. Mallaburn PS, Press MC, Stewart GR (1990) Haustorial structure and function in Striga hermonthica. Journal of Experimental Botany 41: 1355-1360.

10. Heide-Jorgensen HS, Kuijt J (1995) The haustorium of the root parasite Triphysaria (Scrophulariaceae), with special reference to xylem bridge ultrastructure. American Journal of Botany 82(6): 782-797.

11. Prasad Vinayak M (2007) Case study of tobacco cultivation and alternate crops in India. Study conducted as a technical document for the first meeting of the Ad Hoc Study Group on Alternative Crops established by the Conference of the Parties to the WHO Framework Convention on Tobacco Control. 